\title{
REPRESENTAÇÃO E ESTESIA \\ NAS FIGURAS FANTASIOSAS \\ DE O MEU PÉ DE LARANJA LIMA
}

\author{
REPRESENTATION AND ESTHESIA IN THE FANTASY \\ FIGURES OF O MEU PÉ DE LARANJA LIMA
}

\author{
Fernanda Viana de Sena' \\ Sueli Maria da Silva Ramos²
}

1 Doutoranda no Programa de Estudos de linguagem - PPGEL/ Universidade Federal de Mato Grosso do Sul - ferviana01@hotmail.com

2 Doutora em Semiótica e Linguística Geral pelo Fac. de Filosofia, Letras e Ciências Humanas USP, Brasil(2012). Professora Adjunta da Universidade Federal de Mato Grosso do Sul, Brasil - profa. dra.sueliramos@gmail.com 
RESUMO: Este artigo pretende discutir as ideias de representação e estesia no texto literário, em suas manifestações na produção de sentido, partindo dos elementos paratextuais, que indiciam as temáticas envolvidas. Para isso, tomamos como corpus o livro O meu pé de laranja lima (1968), de José Mauro de Vasconcelos, obra em que se evidencia o fenômeno figurativo de modo metafísico. As discussões serão encaminhadas pelas inquietações filosóficas de Foucault (1985) e pelas constituições de sentido de Genette (1987), Greimas (2002; 2008) e Bertrand (2003). A investigação constitui-se por intermédio de trechos do romance infantil e/ou juvenil que apresentam o devaneio infantil e mostram as isotopias fantasiosas, determinantes dos valores inseridos no discurso à luz da semiótica discursiva. A problemática é a do fazer sentido, sob o aspecto da percepção e da emoção, advindas da fantasia, em que é possível supor que o aspecto fantasioso coopere com as ações do sujeito do enunciado, levando-o ao deslumbramento das coisas do mundo e recepcionado pelo enunciatário/leitor.

PALAVRAS-CHAVE: Representação; Estesia; Figuratividade; Texto literário; “O meu pé de laranja lima"

ABSTRACT: This article intends to discuss the ideas of representation and esthesia in the literary text, in its manifestations in the production of meaning, starting from the paratextual elements, which indicate the themes involved. For that, we took as a corpus the book O meu pé de orange lima (1968), by José Mauro de Vasconcelos, a work in which the figurative phenomenon is evidenced in a metaphysical way. The discussions will be guided by the philosophical concerns of Foucault (1985) and by the constitutions of meaning of Genette (1987), Greimas (2002; 2008) and Bertrand (2003). The investigation is constituted by excerpts from the childhood and youth novel that present the childhood daydream and show the fantastical isotopies, determinants of the values inserted in the discourse in the light of the discursive semiotics. The problem is that of making sense, under the aspect of perception and emotion, arising from fantasy, in which it is possible to suppose that the fantasy aspect cooperates with the actions of the subject of the statement, leading him to the dazzle of the things of the world and received by the enunciatee / reader.

KEYWORDS: Representation; Esthesia; Figurativeness; Literary text; “O meu pé de laranja lima" 


\section{INTRODUÇÃO}

É senso comum acreditar que todo ser humano tem capacidade linguística e que se constitui como tal por meio dela. Antes do advento da Linguística, pensamentos filosóficos já prenunciavam essa ideia de que o homem tem habilidade de expressão e essa peculiaridade privativa à espécie desperta o interesse de vários campos do saber. Já as narrativas bíblicas, por exemplo, narram fatos que, alegoricamente, elucidam a linguagem e principiam as hipóteses da origem e da diversidade linguística.

As pesquisas científicas têm tratado as manifestações linguísticas a partir de várias representações. Sejam elas de ordem cognitiva, social e pragmática, encontram recursividade na literatura para ampliar suas áreas de conhecimento e para encontrar, na escrita criativa, o cerne da linguagem. De um modo geral, o universo da linguagem tem sido esteira para discussões que vão desde a sua origem às suas formas de manifestação à luz de teorias das ciências humanas.

Antes de delinear de que maneira a literatura pode contribuir com as investigações filosóficas do ser humano, sobretudo, com o ensino e seus desdobramentos socioculturais, é relevante fazer alguns apontamentos sobre o papel dela em um universo heterogêneo e suas conceptualizações. Dessa maneira, fazendo um levantamento de alguns conceitos, observam-se tentativas de elucidar o fazer literário, uma vez que, de acordo com o filósofo grego Aristóteles, ainda no séc. IV a.C, a arte literária é mimese (imitação). Mais tarde, o pensador e crítico do Romantismo francês Louis de Bonald, no início do século XIX, considerava que literatura é a arte que imita o mundo pela palavra. Recentemente, no contexto dos estudos literários brasileiros, Oswald de Andrade elucida que a poesia existe nos fatos. Guimarães Rosa, por sua vez, sugere que a literatura é "feitiçaria que se faz com o sangue do coração humano". Tais posicionamentos, dos antigos aos, relativamente, recentes, têm como cerne o caráter representativo, como forma de dizer a realidade e as coisas inseridas no mundo natural.

Com o avanço dos estudos literários, a teoria literária investiga, dentro do $f a$ zer literário, um termo específico do que se propunha analisar. Segundo Jakobson (1919, apud SOUZA, 2007, p. 48), “o objeto do estudo literário não é a literatura, mas 
a literariedade, isto é, aquilo que torna determinada obra uma obra literária." Tendo a literatura um caráter recursivo de manifestação da linguagem, ela também é objeto da Linguística e da Semiótica. A contribuição da Semiótica para a reflexão sobre a literatura deve levar em conta a comunicação: não somente o texto, suas estruturas e suas formas, mas também a leitura, suas expectativas, suas interrogações e suas surpresas" (BERTRAND, 2003, p. 399).

Entrar no universo da leitura parece ser tão natural quanto se imagina. Não nos damos conta dos processos cognitivos envolvidos na relação entre o livro e o leitor, muito embora não precisemos monitorar as ações cerebrais que estão ativas durante a leitura. Até porque perder-se-ia, por vez, a "química” que se estabelece entre o que está projetado no discurso por meio do inteligível e do sensível. Isso se torna mais evidente quando se trata do texto literário, em que a organização narrativa subjaz à percepção de cada figura do mundo natural, em uma interação entre os sujeitos que percebem os objetos. De acordo com Discini (2004), os textos literários conduzem a uma hipótese de figurativização e isso ocorre por intermédio dos percursos narrativos em que se consolida o fio temático, legitimando o modo de verdade e como ela é construída.

Para se pensar no uso que se faz da literatura, tem-se alguns conceitos-chave de Aristóteles, que contribuem para a reflexão sobre a representação do mundo por meio de figuras e trazem alguns modos de definir o caráter representativo das artes. Assim, como ilustra o filósofo grego, temos a

mímese: concepção da literatura, e da arte em geral, como imitação, tomando-se esse termo num sentido que tem suscitado inúmeras interpretações; verossimilhança: propriedade da obra literária de, em vez de adequar-se a acontecimentos verdadeiros que lhe sejam exteriores, engendrar situações coerentes e necessárias segundo sua própria lógica interna, situações assim não propriamente assimiláveis à verdade, mas dotadas de verossimilhança, isto é, de semelhança com o vero, o verdadeiro; catarse: propriedade da obra literária de, mediante a criação de situações humanas fortes e comoventes, promover uma espécie de purificação ou clarificação racional das paixões. (SOUZA, 2007, p.25). 
A partir dos postulados aristotélicos, pressupõe-se que a função da Literatura é uma tentativa de representação em uma aproximação com a realidade. A partir dessa característica, nota-se que ela se manifesta por várias denominações, dependendo da temática e das situações comunicativas. "Conjunto de obras distinto pela temática, origem ou público visado - expressões do tipo literatura infanto-juvenil, literatura de massa, literatura feminina, literatura de ficção científica, entre outras" (SOUZA, 2007, p. 45).

Ao notarem-se as temáticas envolvidas em uma obra literária, tem-se, antes do texto em si, elementos que principiam e, de certa forma, antecipam os temas. Levando em consideração os aspectos que conduzem a hipóteses de produção de sentido, Genette (1987, p. 9) elenca componentes fundamentais para a leitura da narrativa, os paratextos editoriais (nome do autor, um título, um prefácio, entre outros elementos que acompanham o enredo). Tais aspectos garantem a presença da narrativa no mundo, a sua existência e a sua recepção.

Considerando ainda o viés temático, o contato com a literatura, como uma maneira de refletir sobre uma das diversas formas de linguagem e a psique humana, permite tanto a análise linguística, em sentido estrito, quanto as análises de significações e representações de um mundo criado. Em termos semióticos, o percurso gerador de sentido poderá se desenvolver por meio dos seguintes níveis: desde o mais superficial até o mais profundo, em que se revelam a tese estruturalista das oposições que sustentarão as possíveis significações reiteradas. Essa recursividade dar-se-á por intermédio de processos isotópicos figurativos e/ou temáticos.

\section{O MEU PÉ DE LARANJA LIMA (1968), DE JOSÉ MAURO DE VASCONCELOS}

A fim de refletir sobre a maneira pela qual as figuras manifestam-se no discurso e como elas projetam a temática da fantasia, desde os paratextos editoriais, dando o efeito de continuidade, os trechos da obra $O$ meu pé de laranja lima, de José Mauro de Vasconcelos servirão de corpus para se pensar na representação e nos afetos vivenciados pelo sujeito do discurso. 
A obra possui uma narrativa desenvolvida por meio de simulacro de linguagem de criança. Nela, o protagonista Zezé e tal aspecto proporcionam certo efeito de ingenuidade à narrativa, levando-nos a crer que o sujeito do enunciado é, de fato, um menino de seis anos. Isso podemos observar no emprego dos termos "meninozinho", "bem-feitinha”, “arvorezinha”, “Seu Julinho" e "passarinho”, entre outras ocorrências. Assim, na formação das palavras, tem-se o radical com o acréscimo do sufixo “-inho”, expressando afetividade.

Apesar disso, é possível levantar algumas discussões sobre relevantes temas. O livro levanta reflexões sobre o afeto e a falta dele, os riscos da ausência parental, maus tratos e, também, o trabalho infantil. Dentre diversas situações que chamam a atenção na obra, é possível observar os devaneios da criança. A narrativa demonstra que a família sofre devido ao desemprego do pai e o protagonista é um garoto que gostava de imaginar coisas. Paralelo a isso, a peraltagem e a hiperatividade do menino são recorrentes e são a causa para ele ser violentado física e psicologicamente pelos membros da família.

No começo, por cerimônia ou porque queria impressionar os vizinhos, me comportava bem. Mas uma tarde recheei a meia preta. Enrolei ela num barbante e cortei a ponta do pé. Depois, onde tinha sido o pé, peguei uma linha bem comprida de papagaio e amarrei. De longe, puxando devagarzinho, parecia uma cobra, e no escuro ela ia fazer sucesso. (...)

Pronto! Lá vinha uma mulher. (...)

O tamanco vinha perto... e zúquete...

(...) A mulher deu um grito tão grande que acordou a rua.

$\mathrm{Ai}$, meu Deus, que eu vou perder o meu filho de seis meses

(VASCONCELOS, 2005, p. 62)

O trecho é uma das passagens que mostra a traquinagem do garoto. Por conseguinte, ele acredita, com veemência, que é uma criança ruim. Associado a isso, pela falta de compreensão e de compaixão dos adultos, Zezé cria um mundo paralelo ao seu, inserindo-se nele e inventando amigos imaginários. Ele faz do pequeno pé de laranja lima, que ficava no fundo do quintal da casa, seu melhor amigo. O título recebe o nome desse novo amigo com a inclusão do pronome possessivo meu. Dessa 
forma, a partir dos estudos dos elementos paratextuais de Genette (1987), é possível depreender que o sujeito considera a árvore sua, antecipando a relação dele com ela.

Além desse paratexto, alguns títulos dos capítulos evocam o aspecto fantasioso. Um exemplo é o capítulo quatro, "O passarinho, a escola e a flor", no qual o sujeito vivencia momentos de imaginação, em uma narrativa secundária à principal e real. Nesse sentido, a criação de um mundo secundário seria capaz de combinar a imaginação e a irrealidade, levando-nos ao contato com um mundo criado, livre da “dominação dos fatos reais", em um processo cognitivo.

Pretende-se estreitar o campo de concentração da análise para a temática da fantasia retratada no romance de José Mauro de Vasconcelos. De acordo com Genette (1987, p. 11), o próprio enquadramento da obra em determinado gênero contribui para a antecipação do discurso a ser proferido, que, no caso da obra analisada, são os gêneros infantil e autobiográfico. Essa última característica, de certa forma, também inscreve o livro no aspecto confessional e introduz a ideia de estilo.

\section{AS FIGURAS COMO (RE)LEITURA DAS COISAS DO MUNDO}

Freud proporcionou as bases da Psicanálise, considerando que o poeta é um fabricante de utopias construídas por experiências e complexos infantis. Ele enxergava na literatura um rico depósito de indícios sobre o subconsciente do homem. Assim, intitulou o complexo de Édipo, usando o drama sofocliano e interpretou Hamlet e Os Irmãos Karamázov como alegoria do amor e ódio incestuoso. Nada obstante, nunca passou de um interesse superficial pela literalidade nem pretendeu elucidar os problemas instaurados nos enredos. O que se pretendia era a análise profunda do âmago e do comportamento humano a partir da manifestação linguística. Esse tipo de empreendimento foi feito também por Bakhtin nas obras de Fiódor Dostoiévsky e por Propp que, em seu livro Morfologia do conto maravilhoso (1984), sistematizou a estrutura das narrativas.

Ao tratar da temática da fantasia, a obra traz a imaginação de Zezé como um elemento transformador de seu estado. Levando em consideração a matriz imagina- 
tiva da mente humana, Bachelard (1988) investigava a imaginação humana que se manifesta, utilizando materiais de proveniência literária. Assim, observava que "as capacidades imaginativas operam na mente humana como inspiração formal, que tem o seu desenvolvimento na novidade, e como inspiração material que correspondem a imagens contidas no fundo do ser" (YLLERA, 1979, p. 51). Levando em consideração essa premissa, há de se pensar que, na obra, o menino opera uma espécie de similitude às coisas da natureza e dos aspectos doxológicos que faziam parte de seu repertório sociocultural.

Foucault (1985, p.23), ao dispor sobre as quatro similitudes, destaca que é preciso ir ao invisível por meio das figuras visíveis, trazendo à luz, por meio da semelhança, a profunda invisibilidade. Em outras palavras, trazer, por meio das representações, as abstrações contidas na mente humana, como uma categoria do pensamento. Nessa perspectiva, o filósofo diz que pensar o sentido das coisas de natureza indecifrável é considerar as figuras do mundo como modo de conveniência, emulação, analogia e simpatia.

Ao tratar daquilo que é visível e do que é invisível, Merleau-Ponty (1961) diz que ver já é um ato de linguagem, que faz das coisas vistas a enunciação das coisas não invisíveis. A partir, há de se pensar que as figuras, que são visíveis, clareiam os temas que, por sua vez, são invisíveis. Assim, em termos semióticos, na leitura da narrativa de José Mauro de Vasconcelos, as figuras fornecem ao enunciatário a presença da temática da fantasia e como o sujeito entra em conjunção com a fantasia, percebendo as coisas do mundo criado pela linguagem.

Os estudos da semiótica discursiva, tendo por base metodológica o percurso gerativo de sentido, têm servido de referencial teórico-metodológico de um número considerável de reflexões desde seu estabelecimento na década de 1960. Há tempos que trabalhos de visadas distintas dispõem-se sobre mecanismos discursivos e seus sujeitos constituintes de um simulacro de realidade. Benveniste, em 1968, dispõe sobre a problemática da natureza do sentido e reflete sobre quem deveria conceber investigações sobre o assunto, se eram os filósofos e/ou os linguistas. Mesmo não chegando à conclusão para o domínio desse conteúdo, ambas as áreas concordam que tal aspecto é fundamental para os estudos fenomenológicos da linguagem. 
No ano de 1970, Greimas analisa que o avanço da Semiótica dava-se por meio das estratégias de apreensão da significação. No entanto, a natureza do sentido ficou em pendência, pois sabia-se onde e como se manifesta o sentido, mas se desconhecia a sua natureza. Em 2002, em Da imperfeição, o semioticista fala sobre a complexidade do sentido e traz aos estudos semióticos o campo do sensível que escapa as barreiras do texto. O que propõe o autor é o sentido associado à experiência humana. Essa perspectiva inscreve-se em um plano sensorialista, que considera a natureza do sentido a partir de notações sensoriais. Tais aspectos emanam das figuras que evocam as relações que a semiótica tem com a fenomenologia, sobretudo com a abordagem de M. Merleau-Ponty sobre percepção.

De acordo com Harkot-de-La-Taille (2016), o que era alcançável do espírito do sentido, por meio das ciências semióticas e semânticas, constituía-se a partir da convencionalidade, de certa forma, imperativa, e de um acordo prévio de troca e da existência de um sistema exterior às consciências individuais. Esse fenômeno apresenta-se por meio dos discursos que expressam o sentido e o transformam dentro do texto.

Deleuze, em Pensamento Nômade (1985), em uma filosofia da experimentação, fala da exterioridade como um enquadramento do pensamento humano. Para o filósofo, os textos são atravessados por um movimento que vem de fora, que não começa na página do livro, nem nas precedentes. Por outro lado, o movimento imaginário das representações salta dos livros e entra em contato com o exterior. De modo genérico, são vias que se cruzam e se fundam, evocando o sentido.

Voltando-se aos pressupostos de Harkot-de-La-Taille (2016, p. 33), “as coisas passam a significar (...) na medida em que sua experiência apresenta pensamento, memória e linguagem, do ponto de vista de uma teoria da significação." Para a autora, o termo significação empregado corresponde à produção de sentido. Esse processo é tão habitual que a necessidade das coisas triviais fazerem sentido passa despercebida.

No livro $O$ meu pé de laranja lima, há uma passagem em que o menino Zezé observa a natureza e é "capturado" por uma cena, habitualmente comum, porém ela afetara-lhe a memória, por meio de um poema e, sobretudo, a sua sensibilidade. 
[...] Deixei ele (Portuga) sentado lá e fui reinar. Descobrir coisas. Como era lindo aquele pedaço de rio. Molhei os pés e vi um mundo de sapinhos pra lá e prá cá na correnteza. Fiquei vendo a areia, os seixos e as folhas sendo puxados pela correnteza. Me lembrei de Glória.

"Deixa-me, deixa-me, fonte!" ${ }^{3}$

Dizia a flor a chorar.

"Eu fui nascida no monte...

Não me leves para o mar."

E a fonte, rápida e fria,

Com um sussurro zombador,

Por sobre a areia corria,

Corria levando a flor.

$[\ldots]$

Glória tinha razão. Aquilo era a coisa mais bonita do mundo. Pena que eu não pudesse contar pra ela que vira a poesia viver. (VASCONCELOS, 2005, p. 151)

No trecho anterior, a experiência do menino ao ver a correnteza do rio e a ação de molhar os pés convocaram a presença da irmã Glória. Para isso, associou o fenômeno natural à poesia lida pela garota. É possível crer que o movimento das águas é o mesmo diariamente, mas não os modos de vê-lo, não os sentidos para ele construídos, pois estes dependem das relações que o repertório de cada pessoa permite estabelecer. O sujeito, então, passa a ver não o correr das folhas na água e sim a sua vida atravessada por um afeto sentido pela poesia. Tal investimento é um processo de construção de sentido de alguém num simulacro de criança, que parece, no momento pueril, ser extremamente sensível. Esse fazer sentido não está nas coisas em si (correnteza, rio, folhas, areia, sapinhos, seixos), mas nas relações que se estabelecem entre o conjunto de figuras e o repertório de conhecimentos, sobretudo, do contato com a poesia. Assim, a passagem representa um momento de deslumbramento diante da experiência, o tempo, que se desenvolvia normalmente, foi suspenso pelo evento e levou o sujeito ao clima estésico.

Para dispor sobre o momento de estesia, utiliza-se a representação mental humana a seguir.

3 Trecho do poema A flor e a Fonte, de Vicente de Carvalho. in: Poemas e Canções, 1908. 


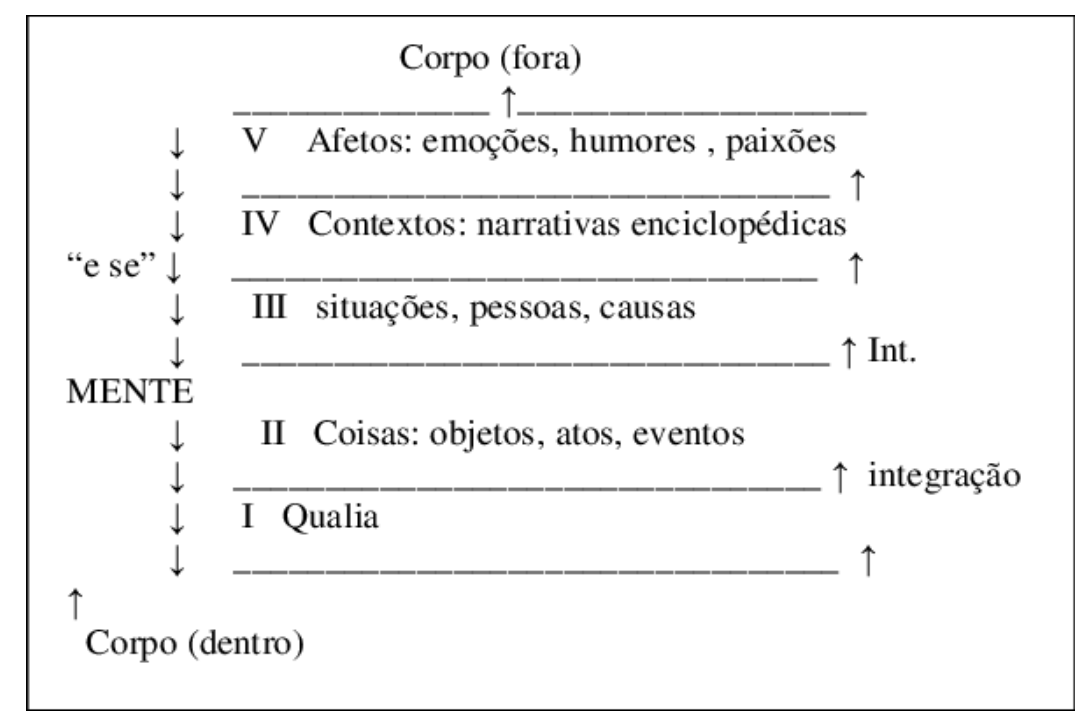

Figura 1: Representação para a arquitetura mental de Brandt Fonte: BRANDT, 2010, p. 27, apud HARKOT-DE-LA-TAILLE, 2016, p. 53

Por meio da representação, Harkot-de-La-Taille (2016) descreve o processo pelo qual o sujeito assume o estágio passional, considerando as integrações graduais dos níveis que comportam os afetos do corpo. Ela diz que as passagens se dão de qualia em coisas, de coisas em situações, de situações em narrativas, ou casos e de narrativas em formas de afetos. Para entender as extremidades dos níveis subjacentes ao processo de significação descritos no quadro, considera-se que

os qualia derivam de processos de percepção físicos e fisiológicos e de e de memória. Já os estados afetivos têm relação com o que ocorre com o modo como o corpo é afetado e como as reações motrizes ou associações mentais são provocadas, na busca de respostas ou reações a situações. (HARKOT-DE-LA-TAILLE, 2016, p. 54)

As cinco camadas são propostas desde o sentir relacionado às sensações até o sentir atinente às emoções. No trecho analisado, o sujeito declara que havia sentido a poesia manifestar-se, por meio da percepção visual e da emoção. “[...] Glória tinha razão. Aquilo era a coisa mais bonita do mundo. Pena que eu não pudesse contar pra ela que vira a poesia viver." A passagem representa o aspecto sensorial em sua concepção amplificada. 
SENSORIALIDADE

SENSAÇÕES

... vira a poesia viver.

\section{EMOÇÕES}

(...) Aquilo era a coisa mais bonita do mundo.

Quadro 1: Representação da sensorialidade

Fonte: autoria nossa

As emoções referem-se à comoção do sujeito e as sensações estão vinculadas às percepções, no caso visuais. Para dispor sobre as percepções, Bertrand (2003) diz que elas "parecem instalar-se no cerne da reflexão sobre a figuratividade", que, segundo Greimas, acerca do acontecimento de apreensão estética, são “objetos que se erguem diante de nós sob forma de figuras do mundo" (GREIMAS, 2002, p. 77, apud BERTRAND, 2003, p. 237).

De acordo com Greimas (1975), é possível compreender que a experiência vivida pelo sujeito no discurso é um fato poético, que se desenvolve a partir de objetos poéticos capazes de figuratizar o trecho como um momento metafísico, transcendental e poético.

Sistematizando as discussões desenvolvidas e os conceitos apontados anteriormente, é possível transpor as figuras sensoriais constantes na passagem para um esquema da representação mental elucidada por Brandt (2010, apud HARKOT-DE-LA-TAILLE, 2016).

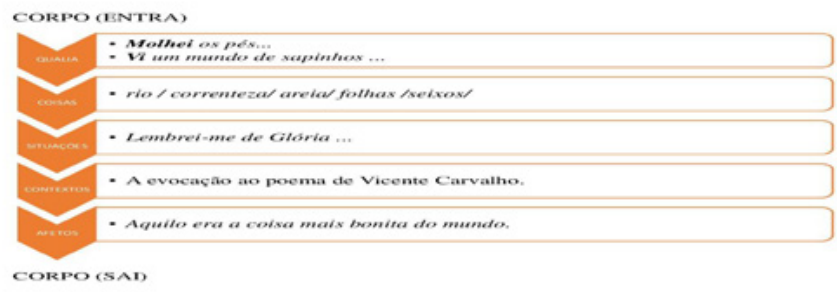

Figura 2: Esquema processual de sensorialidade a partir da representação mental de BRANDT (2010) 
A partir do esquema, percebe-se que o momento de estesia acontece por meio de camadas que se integram, paulatinamente, em um tempo sobreposto ao tempo dos acontecimentos da realidade. Esse modelo de representação faz-nos pensar sobre o sentido que exige critérios fixos, pensando nos níveis mas, sobretudo, dinâmicos em uma perspectiva paradigmática.

A fim de continuar refletindo sobre o deslumbramento e a representação das coisas por meio das palavras, outro trecho da obra de José Mauro de Vasconcelos será utilizado. Antes disso, para corroborar com o que está sendo discutido aqui, é relevante trazer outras concepções de representatividade, pensando nas perspectivas que os semioticistas e pensadores discorrem a partir de análises de textos literários.

No tocante à relação entre palavras e coisas, a formação do sentido lida não só com as palavras, mas com a percepção e a elaboração mental do material sensorial que dão origem ao conceito, considerando que a sensorialidade e as figuras são indispensáveis para a formação de conceitos (MARTINS, 2002). Nesse sentido, o que se propõe é a concepção saussuriana de que as palavras adquirem sentido dentro de um jogo entre palavras no sistema linguístico, e introduzindo o mundo da realidade, das coisas, na formação dos significados. Esse processo apresenta-se como um aspecto criativo e não mecânico.

Para evidenciar a figuratividade como um aspecto de representação, Bertrand (2003, p. 198) aponta que é importante tratar aquela não como ornamentação das coisas, mas, sobretudo, como uma abertura de uma possibilidade de além-sentido, que expõem a imanência do sensível. A definição é um dos saberes semióticos que pode conduzir à hipótese de representação do tema fantasioso da obra $O$ meu pé de laranja lima, que também se manifesta por intermédio da sensorialidade.

Cavouquei o chão com um pauzinho e começava a parar de fungar. Uma voz falou vindo de não sei onde, perto do meu coração:

- Eu acho que sua irmã tem toda razão.

- Sempre todo mundo tem toda a razão. Eu é que não tenho nunca.

- Não é verdade. Se você me olhasse bem, você acabava descobrindo.

Eu levantei assustado e olhei a arvorezinha. Era estranho porque 
sempre eu conversava com tudo, mas pensava que era o meu passarinho de dentro que se encarregava de arranjar fala.

- Mas você fala mesmo?

— Não está me ouvindo?

E deu um risada baixinha.

- Árvore fala por todo canto. Pelas folhas, pelos galhos, pelas raízes. Quer ver? Encoste seu ouvido aqui no tronco que você escuta meu coração bater.

(...) uma coisa ao longe fazia tique... tique

(...) Uma fada me disse que quando um menininho igualzinho a você ficasse meu amigo, que eu ia falar e ser muito feliz (VASCONCELOS, 2005, p. 32-33).

A leitura que se faz do trecho predispõe à antropomorfização instaurada no discurso. Por meio de feixes do mundo natural, é possível compreender um simulacro de narrativa fantasiosa. Nesse sentido, a aparente percepção de fala e de escuta é o que caracteriza a competência humana que a árvore tem.

Levando em consideração ainda a passagem anterior, falar sobre antropomorfização, na maioria das vezes, é tratar de inventividade na idade infantil e pode ser considerada um devaneio. Bachelard (1988, p. 13) considera que a criança, na solidão, pode acalmar as suas angústias, criando um mundo imaginário. $\mathrm{O}$ trecho “Cavouquei o chão com um pauzinho e começava a parar de fungar. [...]" é um momento anterior à imersão do menino ao universo fantasioso, após ele estar triste com os fatos que antecedem o momento mágico. A passagem “[...] Uma voz falou vindo de não sei onde, perto do meu coração [...]" já é efetivamente uma ocorrência fantasiosa. A partir daí, o sujeito, sozinho com o pé de laranja lima, experimenta, pela primeira vez, a conversa com a árvore.

Esse deslumbre é concebido como uma ruptura na vida representada, de acordo com Greimas (2002, p. 21). Em outras palavras, uma fratura, entendida como uma passagem da realidade para a fantasia. Nessa perspectiva, não se trata de uma troca de isotopia textual, em que se tem de um lado o real e do outro o imaginário. Refere-se a uma quebra entre a dimensão cotidiana e o momento de inventividade do sujeito. É considerado um novo estado das coisas, em que a ação inesperada do objeto afeta o sujeito. 
Sobre a inventividade da criança, é longe dos olhos dos adultos que ela conhece a aventura de sonhar, que será mais tarde a aventura dos poetas. Seu devaneio não era simplesmente uma fuga. Era uma ilusão de alçar voo. É notável, no trecho, que o investimento para se conceber a liberdade inventiva seja o devaneio (BACHELARD, 1988, p. 13).

Apesar do aspecto fantasioso da cena, o sujeito percebe-se surpreendido e espantado. "Eu levantei assustado e olhei a arvorezinha. Era estranho porque sempre eu conversava com tudo, mas pensava que era o meu passarinho de dentro que se encarregava de arranjar fala" (VASCONCELOS, 2005, p. 32-33). Por meio da recorrência figurativa dos adjetivos "assustado" e "estranho", provoca-se um efeito de continuidade e duração desse momento de estesia.

Para dispor sobre essa manutenção das figuras, é importante destacar que a isotopia figurativa é a marca do discurso que recobre o tema, completamente, por um ou mais percursos figurativos. A redundância de traços figurativos, a associação de figuras semelhantes confere ao discurso "uma imagem organizada e completa de realidade ou cria a ilusão total do irreal, a que já se fizeram muitas referências. Assegura-se, assim, a coerência figurativa do discurso" (BARROS, 2002, p. 138).

Sob a luz da perspectiva sensorialista, retornando ao aspecto da antropomorfização presente na obra, podemos considerar que trata-se de um evento estésico. O sujeito, quando se dá conta que a árvore pode falar, é surpreendido com estranhamento e, quase instantaneamente, pergunta à árvore por onde ela fala. Assim, tenta-se construir a representação do evento, a partir das figuras que configuram a competência humana [fala/ escuta].

Greimas (2002) diz que a apreensão depende da relação particular entre o sujeito e o objeto de valor. A condição primeira, no trecho, é a voz da árvore, marcada pela fala e pelas figuras usadas para mostrar a antropomorfização. "Árvore fala por todo canto. Pelas folhas, pelos galhos, pelas raízes" (grifos nossos) (VASCONCELOS, 2005, p. 32-33). Assim, a percepção estética se realiza no plano conceitual - é a árvore transfigurada que o menino escuta - o deslumbramento que afeta o sujeito sobremaneira. 


\section{CONSIDERAÇÕES FINAIS}

A fim de refletir sobre a representação das coisas do mundo por meio do texto literário, foi possível atribuir sentido aos trechos analisados à luz das primeiras proposições-fontes da Semiótica Discursiva. Sobretudo, o artigo chegou à hipótese do fazer sentido, sob o aspecto da percepção e da emoção. Assim, os eventos estésicos presentes na tela do parecer fantasioso presente na obra $O$ meu pé de laranja lima (1968) conduzem às discussões propostas.

As figuras que recobrem o tema da fantasia de José Mauro de Vasconcelos são evidenciadas por eventos estésicos e sensíveis, assumidos pela percepção e pela emoção. Conclui-se, por conseguinte, que os devaneios da criança contribuíram para a apreensão do eidético e que, dependendo do repertório construído na infância, é possível apreender sentidos, capazes de levar o indivíduo a um estado de deslumbramento.

A hipótese de figurativização instaurada no discurso ocorre por intermédio dos percursos narrativos em que se consolida o fio temático, legitimando o aspecto fático e um modo de verdade (DISCINI, 2004). Essa característica do texto literário pode ser endossada por conceitos que reforçam a noção de constituição de sentido, que se dá com a combinação de temas e de figuras recorrentes, evidenciados a partir do modo pelo qual o discurso é produzido. Ao considerar essa relação entre o objeto semiótico e o modo de dizer, vale ressaltar os princípios do plano de conteúdo e do plano de expressão. Além disso, é relevante, nesta pesquisa, distinguir a noção de texto e discurso. Para Fiorin (1998), o discurso é "o lugar das coerções sociais, enquanto o texto é o espaço da 'liberdade' individual” (FIORIN, 1998, p. 42).

Além disso, foi possível também notar que o texto literário, em si, já conduz a figurativização, mas essa nem sempre é condição para apreensão estética. Greimas (2002) diz que o evento estético é um "relâmpago passageiro". Então, pensando no percurso figurativo da fantasia, apenas durante o acesso à figuratividade, a estesia acontece. A coisa extraordinária é suprimida pelo encadeamento das ações posteriores. Desse modo, após o sujeito debruçar-se sobre o objeto, a separação dele acontece naturalmente. 


\section{REFERÊNCIAS}

BACHELARD, G. A poética do devaneio. Tradução de Antônio de Pádua Danesi. São Paulo: Martins Fontes, 1988.

BARROS, Diana Luz Pessoa de. Teoria do Discurso; fundamentos semióticos. São Paulo: Atual, 1990.

BARROS, Diana Luz Pessoa de. Teoria semiótica do texto. 4 edição. São Paulo: Ática, 2002.

BERTRAND, Denis. Caminhos da semiótica literária. Bauru, SP: EDUSC, 2003.

COUTINHO, Afrânio. A Literatura no Brasil. Rio de Janeiro: Editorial Sul Americana S.A., 1955.

DELEUZE, Gilles. O Pensamento Nômade. In: MARTON, Scarlett (org.). Nietzsche Hoje? Colóquio de Cerisy. São Paulo: Brasiliense, 1985.

DISCINI, Norma. Intertextualidade e conto maravilhoso. $2^{\text {a }}$ edição. Sao Paulo: Humanitas, 2004.

FIORIN, José Luiz. Elementos de análise do discurso. 3ª edição. São Paulo: Contexto, 1992.

FOUCAULT, Michel. As palavras e as coisas: uma arqueologia das ciências humanas. Trad. Salma Tannus Muchail. 3ª edição. SP: Martins Fontes, 1985.

GENETTE, Gérard. Paratextos editoriais. Tradução de Álvaro Faleiros. Cotia, SP: Ateliê Editorial, 2009.

GREIMAS, Algirdas J. Ensaios de semiótica poética, com estudos sobre Apollinaire, Bataille, Baudelaire, Hugo, Jarry, Malarmé, Michaux, Nerval, Rimbaud, Roubaud. In: Greimas, A. (Org.). Tradução de Heloysa de Lima Dantas. São Paulo: Cultrix/EDUSP, 1975.

GREIMAS, A. J. Da imperfeição. Tradução de Ana Claudia de Oliveira. São Paulo: Hacker Editores, 2002.

HARKOT-DE-LA-TAILLE, Elizabeth. Sentir, Saber, tornar-se: estudo semiótico do percurso entre o sensório e a identidade narrativa. São Paulo: Humanitas: FAPESP, 2016.

MARTINS, Maria Sílvia Cintra. Entre palavras e coisas. São Paulo: Editora UNESP, 2002. 
PROPP, Vladimir I. Morfologia do conto maravilhoso. Rio de Janeiro: Forense Universitária, 1984.

SOUZA, Roberto Acízelo de. Teoria da Literatura. São Paulo: Ática, 2007. Série Princípios.

VASCONCELOS, José Mauro de. O Meu Pé de Laranja Lima. $2^{\mathrm{a}}$ edição, 115a impressão. São Paulo: Editora Melhoramentos, 2005.

YLLERA, Alicia. Estilística, poética e Semiótica literária. Tradução de Evelina Verdelho. Coimbra: Livraria Almedina, 1979. 